\title{
Exchange-Rate Policy and Monetary Information
}

\author{
Kent P. Kimbrough* \\ Department of Economics, Duke University, Durbam NC 27707, USA
}

\begin{abstract}
This paper develops a model of a small open economy in which the presence of local deviations from purchasing power parity give rise to differential information. It is assumed that the monetary authorities are committed to buy and sell foreign exchange in order to support an exchange-rate policy rule. It is demonstrated that exchange-rate policy can influence the distribution of real output (i) if agents possess incomplete and differential information and (ii) if they have contemporaneous money supply (or balance of payments) information. It is also shown that exchange-rate policy can be effective because of 1 ts ability to influence the information content of available monetary data. The argument is turned around and used to support the frequent release of monetary data.
\end{abstract}

Policymakers frequently recommend devaluation as a cure for recession. ${ }^{1}$ The notion is that a devaluation switches aggregate demand from foreign to domestic goods by making foreign goods relatively more expensive. Given some slack in the economy, this increase in aggregate demand will be met by an expansion of real output and employment rather than by domestic price inflation. This policy prescription, in conjunction with doses of expenditure reducing policy as needed, is supported in the economics literature by Meade (1951), by popular textbook adaptations of Mundell's (1963) model (see, for example, Dornbusch and Fischer, 1981), and by Boyer (1978). ${ }^{2}$ However, the ability of devaluation, or more, generally of exchange-rate policy, to influence real output and employment has recently been called into question in much the same way that the effectiveness of monetary policy was called into question by Sargent and Wallace (1975) and others. Models employing the by now familiar rational expectations aggregate supply function, such as Weber (1981), Chan (1982), and Kimbrough (1982, 1983), have all shown that the systematic element of exchange-rate policy does not influence the distribution of real output. That is, from the standpoint of stabilizing real output one exchange-rate rule is as good as any other. This result is also implicit in recent work by Leiderman (1979) and Turnovsky (1981) on (rigidly) fixed exchange-rate regimes.

* I would like to thank Mike Salemi, George Tauchen, Gary Zarkin, and two anonymous referees for their helpful comments.

0261-5606/83/03/0333-14\$03.00 (C) 1983 Butterworth \& Co (Publishers) Ltd 
The purpose of this paper is to outline conditions under which exchange-rate policy can be effective in influencing the distribution of real output even in the presence of a rational-expectations aggregate supply function. The model used to derive these results is an open-economy version of the model presented by Barro (1980) in which agents trade in local goods markets and in an economy-wide asset market. Purchasing power parity is assumed to hold at the aggregate level, but there are local deviations which give rise to diverse information. ${ }^{3}$ It is demonstrated that (i) if agents possess incomplete and differential information and (ii) if they have contemporaneous information on the money supply (or balance of payments), exchange-rate policy can influence the distribution of real output. It is further demonstrated that exchange-rate policy is effective in this instance because it can alter the information content of the money supply (which is an endogenous variable because of the monetary authorities' commitment to buy and sell foreign exchange in order to support their exchange-rate rule). This result is similar in spirit to those presented by Weiss $(1980,1982)$ and King (1982) who have recently shown that monetary policy can alter the distribution of real output by altering the information content of market prices. ${ }^{4}$ However, note that in this case policy gains leverage through its impact on the information content of an observed quantity variable (the money supply) rather than through a price variable (the relative price of money being set by an exchange-rate rule).

The remainder of the paper is organized as follows. Section I outlines the model. In Section II the case of full current information is examined while in Section III the case of incomplete current information is discussed. In Section III it is assumed that agents observe a monetary aggregate that provides noisy information about the current money supply. The information extraction problem facing agents is discussed, and the exchange-rate policy effectiveness results mentioned previously are derived. Concluding remarks are presented in Section IV.

\section{The Model}

\section{IA. Setup}

The country under consideration is assumed to be small in both goods and asset markets. Agents are located in spatially separated markets indexed by the letter $z$. One good is produced and consumed each period and there is no trade in goods across markets during a period. The distinguishing feature of each local market is that the agents residing there choose a foreign trading partner at the start of each period. Because different local markets have different foreign trading partners, and because the foreign country is also assumed to be composed of a collection of spatially separated markets, realized commodity prices differ from market to market as described by

$$
P_{t}(z)=S_{t}+P_{t}^{*}(z)
$$

and

$$
P_{t}^{*}(z)=P_{t}^{*}+z
$$

where $P_{t}(z)$ is the (natural logarithm of the) local commodity price in market $z, S_{t}$ is the (natural logarithm of the) exchange rate defined as the domestic currency price 
of foreign exchange, $P_{t}^{*}(z)$ is the (natural logarithm of the) foreign currency price of goods in market $z^{\prime}$ s trading partner, $P_{t}^{*}$ is the average of this price across all markets (later referred to as the economy-wide foreign price), and $z_{t}$ is a random variable that is normally and independently distributed with mean zero and variance $\sigma_{z}^{2}$. Since the home country is small, domestic agents take the distribution of foreign prices as given. Combining $\langle 1\rangle$ and $\langle 2\rangle$ it can be shown that

$$
P_{t}(z)=S_{i}+P_{t}^{*}+z_{t}
$$

which implies that the economy-wide average of local commodity prices (the price level) is

$$
P_{t}=S_{t}+P_{t}^{*}
$$

Therefore, purchasing power parity holds at the aggregate level, but there are local deviations reflected by $z$. For simplicity, it is also assumed that the economy-wide foreign price varies over time according to

$$
P_{t}^{*}=P_{t-1}^{*}+v_{t}
$$

where the innovation $v_{t}$ is normally and independently distributed with mean zero and variance $\sigma_{\nu}^{2}$.

The (natural logarithm of the) supply of real output in market $z, y_{t}(z)$, depends positively on the relative price of current goods in terms of future goods, or the real rate of return, perceived by agents in market $z, r_{t}(₹)$, as given by

$$
y_{t}(z)=\alpha r_{i}(z)+u_{i} ; \quad r_{t}(z)=P_{t}^{*}(z)-E_{q} P_{t+1}^{*}+i^{*}
$$

where the aggregate supply shock, $u_{t}$, is normally and independently distributed with mean zero and variance $\sigma_{z}^{2}$ and $i *$ is the nominal interest rate on foreign bonds. ${ }^{5}$ The relative price term can be explained as follows: A sale this period allows agents to accumulate $P_{t}^{*}(z)$ plus the nominal rate of return on the foreign bond by period $t+1$, while a sale next period is expected to yield $E_{z} P_{t+1}^{*}$ which is the expected future foreign price conditioned on the information available to agents in market $q .{ }^{6}$ Comparison of these yields results in the relative price term $r_{t}(z)=$ $P_{t}^{*}(z)-E_{z} P_{t+1}^{*}+i *$. When the relative price of current goods in terms of future goods increases, agents substitute future for current leisure and thus increase their current labor supply. This results in an increase in real output as shown by $\langle 4\rangle{ }^{7}$

Turning to the asset side of the model, it is assumed that agents hold two assets-domestic money and foreign bonds. These assets are traded in an economy-wide market as in Barro (1980), and for this reason agents in all markets observe the exchange rate and the foreign nominal interest rate. The (natural logarithm of the) aggregate demand for money, $M_{t}$, depends on the economy-wide levels of local commodity prices, teal output, and the perceived opportunity cost of holding money which are given by $P_{t}, y_{t}$, and $i_{t}$. The money demand function is assumed to take the form

$$
M_{t}=P_{t}+\phi y_{t}-\lambda i_{t}
$$

The opportunity cost of holding money, as perceived by agents in market $q$, is the foreign nominal interest rate plus the expected rate of depreciation of the domestic currency, $E_{q} S_{t+1}-S_{t}{ }^{8}$ Averaging across markets this implies that

$$
\left.i_{t}=i^{*}+\overline{\left(E_{z} S_{t+1}\right.}-S_{t}\right)
$$


where $\overline{E_{z} S_{t+1}}$ is the economy-wide average of local expectations concerning next period's exchange rate. Using this in the preceding expression, it follows that the demand for money at time $t$ is

$$
\left.M_{t}=P_{t}+\phi y_{t}-\lambda\left[i *+\overline{E_{z} S_{t+1}}-S_{t}\right)\right]
$$

Finally, it is assumed that policymakers have decided not to allow the domestic currency to float freely, but instead have decided to intervene in the foreign exchange market so that the exchange rate follows some prearranged policy rule. For simplicity, the exchange rate is assumed to be set according to the rule ${ }^{9}$

$$
S_{t}=S_{t-1}+\rho_{\nu} v_{t-1}+\rho_{t} u_{t-1}
$$

where $\rho_{v}$ is a policy parameter capturing the extent to which exchange-rate adjustments are used to offset $\left(\rho_{v}<0\right)$ or reinforce the impact of previous economy-wide foreign price shocks on domestic prices, and $\rho_{u}$ measures the extent to which the exchange rate is adjusted in response to previous aggregate supply shocks. This policy rule can easily be generalized to allow for more complicated feedback from prior events to the exchange rate without altering any of the conclusions concerning the effects of exchange-rate policy on the distribution of real output that emerge from the paper. ${ }^{10}$

\section{IB. Equilibrium}

Because the monetary authorities are committed to buy and sell foreign exchange in order to support the exchange-rate rule $\langle 6\rangle$, the money supply is an endogenous variable that adjusts, through the balance of payments, to maintain asset market equilibrium. In addition to the money supply, the model also determines equilibrium values for local commodity prices, relative prices, and teal output in the following manner: Using $\langle 1\rangle-\langle 3\rangle$ and the definition of the relative price variable it can be shown that in equilibrium

$$
r_{t}(z)=i^{*}+z_{t}+\left(v_{t}-E_{z} v_{t}\right)
$$

Using this in $\langle 4\rangle$ yields

$$
y_{t}(z)=\alpha\left(i^{*}+z_{t}\right)+\alpha\left(v_{t}-E_{z} v_{t}\right)+u_{t}
$$

as the equilibrium level of real output in market $z$. Substituting $\langle 2\rangle,\langle 3\rangle$, and $\langle 6\rangle$ into $\langle 1\rangle$ it can be seen that

$$
P_{t}(z)=S_{t-1}+\rho_{i} v_{t-1}+\rho_{s} u_{t-1}+P_{t-1}^{*}+v_{t}+z_{t}
$$

Then, averaging $\langle 8\rangle$ and $\langle 9\rangle$ across all markets and substituting the resulting expressions in $\langle 5\rangle$, it can be seen that the money supply must satisfy

$$
\begin{array}{r}
M_{t}=S_{i-1}+\rho_{r} v_{t-1}+\rho_{u} u_{t-1}+P_{t-1}^{*}+(\phi \alpha-\lambda) i^{*}+(1+\phi \alpha) v_{t} \\
+\phi u_{t}-\left(\phi \alpha+\lambda \rho_{v}\right) \overline{E_{z} v_{t}}-\lambda \rho_{u} \overline{E_{z} u_{t}}
\end{array}
$$

where use has also been made of the fact that $\langle 6\rangle$ implies

$$
\overline{E_{z} S_{t+1}}=S_{t}+\rho_{v} \overline{E_{z} v_{t}}+\rho_{z} \overline{E_{q} u_{t}}
$$

Expressions $\langle 7\rangle-\langle 10\rangle$ characterize the economy's equilibrium. As in all rationalexpectations models, the properties of this equilibrium depend crucially on the 
information that agents possess at the time they form their expectations. The following sections consider alternative specifications of agents' information sets and their implications for the effectiveness of exchange-rate policy.

\section{Full Current Information}

The case of full current information, while not likely to characterize reality, serves as a benchmark for measuring the fluctuations in real output and employment over the course of the business cycle that result from imperfect information.

When agents possess full current information $E_{z} v_{t}=v_{t}$ and $E_{z} u_{t}=u_{t}$, and it follows immediately from $\langle 10\rangle$ that the full current information value of the money supply (denoted by a tilde) is

$$
\tilde{M}_{t}=M_{t}^{0}+\left(1-\lambda \rho_{v}\right) v_{t}+\left(\phi-\lambda \rho_{u}\right) u_{t}
$$

where

$$
M_{i}^{0}=S_{t-1}+\rho_{v} v_{t-1}+\rho_{u} u_{t-1}+P_{t-1}^{*}+(\phi \alpha-\lambda) i^{*}
$$

is that part of the current period's money supply that can be predicted solely on the basis of the information available to agents at the end of period $t-1$. In addition, it follows from $\langle 7\rangle$ and $\langle 8\rangle$ that under the assumption of full current information

$$
\tilde{r}_{t}(z)=i^{*}+z^{t}
$$

and

$$
\tilde{y}_{t}(z)=\alpha\left(i^{*}+z_{t}\right)+u_{t}
$$

A fully perceived positive shock to local commodity prices $\left(z_{t}>0\right)$ leads agents in market $z$, to increase their real output relative to the aggregate level, $\tilde{y}_{i}=\alpha i *+u_{i}$. The reason for this is that agents are aware that the real rate of return in their market is unusually high, its 'normal' level being $\tilde{r}_{t}=i^{*}$, and they wish to take advantage of this opportunity.

Expressions $\langle 11\rangle$ and $\langle 12\rangle$ reveal two important insights into the workings of exchange-rate policy. First, it is apparent from $\langle 11\rangle$ that exchange-rate policy, and in particular the choice of the policy parameters $\rho_{\nu}$ and $\rho_{u}$, can influence the full current information value of the money supply, and by implication the balance of payments. For instance, by setting $\rho_{t}=1 / \lambda$ and $\rho_{t}=\phi / \lambda$, the (full current information) balance of payments could be made perfectly predictable since $\tilde{M}_{t}=M_{0}$ in this case. In a model with a more elaborate asset structure, if the policymakers objective function attached weight to minimizing the costs of holding international reserves, this might be a force working to push the optimal values of $\rho_{i}$ and $\rho_{u}$ toward $1 / \lambda$ and $\phi / \lambda$, as the more predictable the balance of payments the smaller the level of reserves that are likely to be necessary to support the exchange rate. Second, as can be seen from $\langle 12\rangle$, exchange-tate policy cannot influence the full current information value of real output. Therefore, the benchmark against which fluctuations in real output over the course of the business cycle are measured in Section III is unaffected by the particular exchange rate rule adopted by policymakers.

\section{Incomplete Information}

In general, agents will not act on the basis of full current information, but will have to base their current period supply and demand decisions on incomplete 
information. At a minimum the information that agents have at their disposal includes the market prices of the goods and assets they buy and sell. These prices include their local commodity price $P_{t}(z)$, the exchange rate $S_{i}$, and the nominal interest rate on foreign bonds $i * .{ }^{11}$ Following King (1981) it is also assumed that agents observe a monetary aggregate which conveys noisy information about the current money supply. The remainder of this section outlines the information extraction problem confronting agents and examines the role of exchange-rate policy. The key feature of the model that accounts for the policy implications that are discussed in this section is that the observed monetary aggregate is an endogenous variable that reflects market conditions, and as such conveys useful information to agents.

\section{A. Expectations Formation}

As can be seen from the presentation of the model in Section I, in order to make their current period supply and demand decisions agents must form conditional expectations of the current shocks to aggregate supply and to economy-wide foreign prices, $u_{t}$ and $v_{i}$. Although they have at their disposal three market prices, in the simple framework used here only one of them, the local commodity price, yields any information about current economic conditions. The reason for this is that the exchange rate, being fixed according to the feedback rule $\langle 6\rangle$, does not respond to current market conditions and hence yields no information on the current state of the economy. That is, when the exchange rate is set by policy, rather than determined by market forces, its information content is nil. ${ }^{12}$ In addition, the simplifying assumption that the foreign nominal interest rate is constant obviously implies that it also fails to provide useful information. ${ }^{13}$

The knowledge agents in market $z$ possess of market prices amounts to knowledge of the linear combination of shocks given by

$$
P_{t}(z)-S_{t}-P_{t-1}^{*}=v_{t}+z_{t}
$$

In addition to this agents are assumed to observe a monetary aggregate, $\hat{M}_{t}$, which contains information about the current money supply as specified by

$$
\hat{M}_{t}=M_{t}+x_{t}
$$

The random variable $x_{t}$ is assumed to be normally and independently distributed with mean zero and variance $\sigma_{x}^{2}$, and is intended to capture the measurement error of the observed monetary aggregate. The actual money supply is still given by $\langle 10\rangle$. In conjunction with the preceding expression this implies that the information conveyed to agents by the observed monetary aggregate is given by

$$
\hat{M}_{t}-M_{t}^{0}=(1+\phi \alpha) v_{t}+\phi u_{t}+x_{t}-\left(\phi \alpha+\lambda \rho_{v}\right) \overline{E_{z} v_{t}}-\lambda \rho_{u} \overline{E_{z} u_{t}}
$$

Therefore, agents' expectations of the current period economy-wide foreign price shock and the current period aggregate supply shock are given by

$$
E_{z} v_{t}=a_{1}\left(v_{t}+z_{t}\right)+a_{2}\left(H_{p} v_{t}+H_{u} u_{t}+H_{x} x_{i}\right)
$$

and

$$
E_{z} u_{t}=b_{1}\left(v_{t}+z_{i}\right)+b_{2}\left(H_{v} v_{t}+H_{u} u_{i}+H_{x} x_{i}\right)
$$


where the information content of the observed monetary aggregate has been written as

$$
\hat{M}_{t}-M_{\imath}^{0}=H_{\nu} v_{t}+H_{u} u_{t}+H_{x} x_{t}
$$

and the $H$ 's are (as yet) undetermined coefficients. Rational expectations requires that when $\langle 14\rangle-\langle 16\rangle$ are substituted into $\langle 13\rangle$ the resulting expression holds as an identity. Thus rational expectations requires that ${ }^{14}$

$$
\begin{aligned}
& H_{i}=\frac{1+\phi \alpha-\left(\phi \alpha+\lambda \rho_{t}\right) a_{1}-\lambda \rho_{u} b_{1}}{1+\left(\phi \alpha+\lambda \rho_{t}\right) a_{2}+\lambda \rho_{u} b_{2}} \\
& H_{u}=\frac{\phi}{1+\left(\phi \alpha+\lambda \rho_{v}\right) a_{2}+\lambda \rho_{u} b_{2}}
\end{aligned}
$$

and

$$
H_{x}=\frac{1}{1+(\phi \alpha+\lambda \rho) a_{2}+\lambda \rho_{u} b_{2}}
$$

As shown in the appendix, the solutions for the regression coefficients in $\langle 14\rangle$ and $\langle 15\rangle \operatorname{are}^{15}$

$$
\begin{array}{ll}
a_{1}=\sigma_{\nu}^{2}\left(H_{u}^{2} \sigma_{u}^{2}+H_{x}^{2} \sigma_{x}^{2}\right) / \Delta ; & a_{2}=H_{\nu} \sigma_{v}^{2} \sigma_{z}^{2} / \Delta \\
b_{1}=-H_{v} H_{u} \sigma_{v}^{2} \sigma_{u}^{2} / \Delta ; & b_{2}=H_{u} \sigma_{u}^{2}\left(\sigma_{\nu}^{2}+\sigma_{z}^{2}\right) / \Delta
\end{array}
$$

where $\Delta=\sigma_{z}^{2}\left(H_{v}^{2} \sigma_{t}^{2}+H_{u}^{2} \sigma_{u}^{2}+H_{x}^{2} \sigma_{x}^{2}\right)+\sigma_{v}^{2}\left(H_{u}^{2} \sigma_{u}^{2}+H_{x}^{2} \sigma_{x}^{2}\right)>0$. As an equilibrium condition it must be true that market expectations are formed in the same manner as individual expectations since all agents are alike (except for being located in different markets). This equilibrium condition can be imposed by taking account of the dependence of the $H$ 's on market expectations. Formally this requires substituting $\langle 17\rangle-\langle 19\rangle$ into the solutions for the regression coefficients given by $\langle 20\rangle$, and then solving for closed-form solutions for them (i.e., for the $a$ 's and the $b$ 's). However, as shown in the appendix, this leads to fifth order polynomials in the regression coefficients, and such complex polynomials are not readily solved. Fortunately though, much can be said about the model's implications for exchange-rate policy without obtaining a closed-form solution for the model.

\section{IIB. Implications}

Using $\langle 14\rangle$ in $\langle 8\rangle$ and recalling $\langle 12\rangle$, it can be shown that

$$
y_{t}(z)-\tilde{y}_{t}(z)=\alpha\left[\left(1-a_{1}-a_{2} H_{\nu}\right) v_{t}-a_{2} H_{t} u_{t}-a_{1} z_{t}-a_{2} H_{x} x_{t}\right]
$$

From the solutions for the $a$ 's given by $\langle 20\rangle$ it can be seen that

(i) $0 \leqslant 1-a_{1}-a_{2} H_{v} \leqslant 1$ and $0 \leqslant a_{1} \leqslant 1$

(ii) $a_{1}+a_{2} H_{v}=a_{1}=0$ when $\sigma_{v}^{2}=0$

(iii) $a_{1}+a_{2} H_{i^{\prime}}=a_{1}=1$ when $\sigma_{z}^{2}=0$

As can be seen from $\langle 21\rangle$, real output responds 'too much' to economy-wide (or aggregate) foreign price shocks and 'not enough' to local (or relative) shocks. In 
interpreting this result it is helpful to note that since agents observe the linear combination of shocks given by

$$
P_{t}^{*}(z)-S_{t}-P_{t-1}^{*}=v_{t}+z_{t}
$$

expectational consistency requires that

$$
E_{z} v_{t}+E_{z} z_{t}=v_{t}+z_{t}
$$

or that

$$
v_{t}-E_{z} v_{t}=E_{z} z_{t}-z_{t}
$$

Therefore, when there is a positive shock to economy-wide foreign prices agents underestimate the magnitude of this shock and thus expectational consistency implies that they also overestimate the magnitude of the local shock. Hence agents perceive the real rate of return in their market to be higher than it in fact turns out to be, and they thus increase their supply of real output more than they would if they were fully informed. Similarly, in response to a positive local shock $\left(z_{>}>0\right)$, agents perceive the real rate of return in their market to be lower than it turns out to be, and hence they fail to increase real output as much as they would if they knew the true source of the shock. In the extreme cases where $\sigma_{v}^{2}=0$ or $\sigma_{z}^{2}=0$, real output is always at its full current information level since agents are no longer uncertain about the source of a change in local commodity prices. ${ }^{16}$ Additionally, it can also be seen that when the measurement error of the observed monetary aggregate is extremely large and unpredictable, i.e., when $\sigma_{x}^{2} \rightarrow \infty,\langle 21\rangle$ reduces to

$$
y_{t}(z)-\tilde{y}_{i}(z)=\alpha(1-\gamma) v_{t}-\alpha \gamma z_{t}
$$

where

$$
\gamma=\sigma_{v}^{2} /\left(\sigma_{v}^{2}+\sigma_{z}^{2}\right)
$$

It can easily be demonstrated that this is the expression for the deviation of real output from its full current information value that would have been obtained had it been assumed that agents did not observe the monetary aggregate $\hat{M}_{t}$. This makes intuitive sense since observing a totally noisy signal fails to provide any useful information.

Perhaps the most significant feature of $\langle 21\rangle$ is that it implies that exchange-rate policy can influence the distribution of real output. This follows from the fact that the choices of the policy parameters $\rho_{\nu}$ and $\rho_{u}$ will, in general, affect the coefficients of the current period shocks in $\langle 21\rangle$ through their dependence on the $a$ 's and the $b$ 's. ${ }^{17}$ In fact, the following proposition can easily be demonstrated to be true:

Exchange-rate policy exerts real effects, and in particular influences the distribution of real output, (i) if agents possess incomplete and differential information and (ii) if agents have contemporaneous information on the money supply (or balance of payments).

That the effectiveness of exchange-rate policy requires that agents have (useful) contemporaneous money supply information is readily apparent from $\left\langle 21^{\prime}\right\rangle$ since the policy parameters $\rho_{v}$ and $\rho_{u}$ do not appear on the right-hand side of that expression. This suggests, and indeed it is the case, that exchange-rate policy influences the distribution of real output by altering the information content of the observed monetary aggregate, $\hat{M}_{t}$. More will be said about this shortly.

To see that incomplete and differential information is required for exchange-rate 
policy to be effective, consider the case where $\sigma_{z}^{2}=0$. In this case the differential information aspects of the model disappear and, although agents still have incomplete information, ${ }^{18}$ real output is always equal to its full current information value. Since full current information real output is not affected by exchange-rate policy it follows that exchange-rate policy cannot influence the distribution of real output unless agents have incomplete and differential information-incomplete information alone is not enough.

Insight into the mechanism through which exchange-rate policy attains effectiveness can be gained by examining expression $\langle 13\rangle$ which describes the information content of the observed monetary aggregate. For convenience $\langle 13\rangle$ is repeated below and is broken down into two components:

$$
\hat{M}_{t}-M_{t}^{0}=\underbrace{(1+\phi \alpha) v_{t}+\phi u_{t}+x_{t}-}_{\begin{array}{c}
\text { aggregate shocks } \\
\text { component }
\end{array}}-\frac{\left(\phi \alpha+\lambda \rho_{i}\right) \overline{E_{z} v_{t}}-\lambda \rho_{u} \overline{E_{z} u_{t}}}{\begin{array}{c}
\text { market expectations } \\
\text { component }
\end{array}}
$$

If agents in all markets have the same information then

$$
E_{z} v_{t}=\overline{E_{z} v_{t}} \text { and } E_{z} u_{t}=\overline{E_{z} u_{t}} \text {, }
$$

and the information conveyed to agents by the observed monetary aggregate consists solely of the aggregate shocks component of $\langle 13\rangle$. Therefore, exchangerate policy cannot influence the information at agents disposal in any way, nor can it influence the accuracy of their forecasts. Now, it can easily be seen from $\langle 8\rangle$ and $\langle 12\rangle$ that

$$
y_{t}(z)-\tilde{y}_{t}(z)=\alpha\left(v_{t}-E_{z} v_{t}\right)
$$

from which it follows that unless exchange-rate policy can influence the accuracy of agents' forecasts it cannot influence the distribution of real output. Therefore, when agents in all markets have the same information exchange-rate policy will be ineffective. However, when agents have differential information they will be uncertain about the market expectations component of $\langle 13\rangle$. Exchange-rate policy can, in this instance, influence the information content of the observed monetary aggregate because of its ability to affect the market expectations component of $\langle 13\rangle$ both directly and indirectly (through the dependence of $\overline{E_{z} v_{t}}$ and $\overline{E_{z} u_{i}}$ on $\rho_{v}$ and $\rho_{u}$ ), and can thus influence the distribution of real output. ${ }^{19}$ This result is an open economy extension of results derived in the closed economy context by Weiss (1980, 1982) and King (1982). As in those papers, the key to the result is that agents with incomplete and differential information are trading in a common market (in this case an economy-wide asset market), and they observe a variable in this market (in this case the monetary aggregate $\hat{M}_{t}$ ) that reflects economy-wide average expectations.

Finally, subtracting $\langle 11\rangle$ from $\langle 10\rangle$ and using $\langle 14\rangle$ and $\langle 15\rangle$ it can be shown that

$$
\begin{aligned}
M_{t}-\tilde{M}_{t}=[ & \left.\left(\phi \alpha+\lambda \rho_{v}\right)\left(1-a_{1}-a_{2} H_{v}\right)-\lambda \rho^{u}\left(b_{1}+b_{2} H_{v}\right)\right] v_{t} \\
& -\left[\left(\phi \alpha+\lambda \rho_{v}\right) a_{2} H_{u}-\lambda \rho_{u}\left(1-b_{2} H_{u t}\right)\right] u_{t}-\left[\left(\phi \alpha+\lambda \rho_{v}\right) a_{2}+\lambda \rho_{u} b_{2}\right] H_{x} x_{t}
\end{aligned}
$$

Little can be said about how the three economy-wide shocks affect the distribution of the money supply (or balance of payments) without obtaining a closed-form solution to the model. However, three general points can be made. First, 
exchange-rate policy can influence the distribution of the money supply. This should come as no surprise since both the exchange rate and the money supply are nominal variables. Second, the money supply (or balance of payments) can be stabilized at its full current information value by setting $\rho_{\nu}=-\phi \alpha / \lambda$ and $\rho_{u}=0 .{ }^{20}$ Third, local shocks do not influence the money supply (balance of payments) except to the extent that they affect expectations (through the $a$ 's, $b$ 's, and $H$ 's). This follows from the fact that the money supply adjusts through the balance of payments to equilibrate the asset market, and since the asset market is economy wide local shocks simply 'washout'.

\section{Conclusion}

This paper has developed a model of a small open economy in which the presence of local deviations from purchasing power parity give rise to differential information. It was assumed that policymakers eschewed allowing the exchange rate to float freely, choosing instead to fix the exchange rate according to a feedback rule. It was demonstrated that only if agents possess incomplete and differential information, and only if they also have contemporaneous (but perhaps noisy) information on the money supply (or balance of payments), will exchange-rate policy be able to influence the distribution of real output. This exchange-rate policy effectiveness proposition is related to the monetary policy effectiveness results recently proposed by Weiss (1980, 1982) and King (1982) and extended to the open economy by Kimbrough (1983). It differs, however, in that the variable whose information content policy alters, and through which it attains effectiveness is a quantity variable rather than a market price.

In light of these results, and without empirical work, one's assessment of the usefulness of exchange-rate policy as a tool of stabilization policy depends on one's beliefs about the accuracy and availability of contemporaneous money supply information. However, the results of the paper can also be used to provide a two-pronged argument in favor of providing frequent and accurate monetary data. ${ }^{21}$ First, it is well known that central banks often attempt to conceal their foreign exchange market operations from the public. It is usually argued that this is necessary in order to maintain an orderly market for foreign exchange (i.e., to prevent runs on a particular currency, etc.). However, if agents do not observe other monetary aggregates this may prevent exchange-rate policy from being an effective tool of stabilization policy. By releasing reliable information on their foreign exchange market operations (or other monetary data) at regular intervals the central bank may, therefore, open up a channel through which exchange-rate policy may establish itself as an independent instrument for combating the business cycle. Second, even if exchange-rate policy is poorly concerved (in the sense that policy parameters like $\rho_{v}$ and $\rho_{u}$ are not chosen wisely or that it is erratic), frequent disclosure of reliable monetary data will help to reduce the severity of the business cycle in a small open economy. This follows from the fact that with more information at their disposal agents will be able to more accurately assess the state of the economy, and hence deviations of real output from its full current information value over the course of the business cycle will be reduced when more, rather than less, monetary information is made available. ${ }^{22}$ Thus public avalability of monetary data can be supported in terms of its ability to dampen fluctuations in real output and employment simply by virtue of being made available, and on the grounds that it may add another weapon to the policymaker's arsenal. Since the former argument 
is independent of one's view as to whether or not putting another instrument at policymakers disposal is likely to help matters (i.e., to help reduce the amplitude of the business cycle), the case for releasing reliable monetary data at frequent intervals appears to be a strong one. ${ }^{23}$

\section{Appendix}

Thts appendix outlines the procedure used to obtain the solutions for the regression coefficients $a_{1}, a_{2}, b_{1}$, and $b_{2}$ that are given by $\langle 20\rangle$ of the text. As noted in the text, these are not closed form solutions, so this appendix also sketches the steps involved in obtaining such solutions.

Conceptually, one can view agents as using their knowledge of the structure and past history of the economy to run the regressions

$$
v_{i}=a_{1}\left(v_{t}+z_{t}\right)+a_{2}\left(H_{z^{\prime}} v_{t}+H_{u} u_{t}+H_{x} x_{t}\right)+\varepsilon_{v t}
$$

and

$$
u_{t}=b_{1}\left(v_{t}+z_{t}\right)+b_{2}\left(H_{t} v_{t}+H_{v} u_{t}+H_{x} x_{t}\right)+\varepsilon_{u t}
$$

where $E_{\chi} \varepsilon_{v t}=E_{q} \varepsilon_{u t}=0$. From these regressions the variances of the forecast errors $\varepsilon_{t t}$ and $\varepsilon_{u t}$ can be shown to be

$$
E_{\gamma} \varepsilon_{v t}^{2}=\left(1-a_{1}-a_{2} H_{v}\right)^{2} \sigma_{v}^{2}+a_{1}^{2} \sigma_{z}^{2}+a_{2}^{2}\left(H_{u}^{2} \sigma_{u}^{2}+H_{x}^{2} \sigma_{x}^{2}\right)
$$

and

$$
E_{z} \varepsilon_{u t}^{2}=\left(1-b_{2} H_{u}\right)^{2} \sigma_{u}^{2}+\left(b_{1}+b_{2} H_{v}\right)^{2} \sigma_{v}^{2}+b_{1}^{2} \sigma_{z}^{2}+b_{2}^{2} H_{x}^{2} \sigma_{x}^{2}
$$

From $\langle 23\rangle$ it can be seen that the first-order conditions for minimizing the variance of the forecast errors associated with predicting $v_{t}$ (i.e., the orthogonality conditions) are

$$
\frac{\partial E_{z} \varepsilon_{v t}^{2}}{\partial a_{1}}=-\left(1-a_{1}-a_{2} H_{v}\right) \sigma_{v}^{2}+a_{1} \sigma_{z}^{2}=0
$$

and

$$
\frac{\partial E_{\chi} \varepsilon_{j i}^{2}}{\partial a_{2}}=-H_{\nu}\left(1-a_{1}-a_{2} H_{v}\right) \sigma_{r}^{2}+a_{2}\left(H_{u}^{2} \sigma_{t}^{2}+H_{x}^{2} \sigma_{x}^{2}\right)=0
$$

Similarly, from $\langle 24\rangle$ it can be shown that the orthogonality conditions for the $u_{t}$ regression are

$$
\frac{\partial E_{i} \varepsilon_{u t}^{2}}{\partial b_{1}}=\left(b_{1}+b_{2} H_{i^{\prime}}\right) \sigma_{v}^{2}+b_{1} \sigma_{z}^{2}=0
$$

and

$$
\frac{\partial E_{z} \varepsilon_{u t}^{2}}{\partial b_{2}}=-H_{t \prime}\left(1-b_{2} H_{u}\right) \sigma_{z}^{2}+H_{n}\left(b_{1}+b_{2} H_{i^{\prime}}\right) \sigma_{u^{\prime}}^{2}+b_{2} H_{x}^{2} \sigma_{x}^{2}=0
$$

The orthogonality conditions $\langle 25\rangle$ and $\langle 26\rangle$ can be solved for $a_{1}$ and $a_{2}$ while $\langle 27\rangle$ and $\langle 28\rangle$ can be solved for $b_{1}$ and $b_{2}$. The solutions are those presented in $\langle 20\rangle$ of the text.

The solutions given by $\langle 20\rangle$ are not in closed form but, as discussed in the text, closed-form solutions can in principle be obtained by imposing the equilibrium condition that the $H$ 's be given by $\langle 17\rangle-\langle 19\rangle$. To illustrate how this would work, consider how a closed-form solution for $a_{1}$ could be obtained. To begin, the expression for $a_{1}$ given by $\langle 20\rangle$ can be rewritten as

$$
a_{1} \Delta=\sigma_{\nu}^{2}\left(H_{u}^{2} \sigma^{2}+H_{x}^{2} \sigma_{x}^{2}\right)
$$

Using the definition of $\Delta$ in $\langle 29\rangle$, substituting for the $H$ 's from $\langle 17\rangle-\langle 19\rangle$, and multiplying both sides of the resulting expression by $\left[1+\left(\phi \alpha+\lambda \rho_{v}\right) a_{2}+\lambda \rho_{i i} b_{2}\right]^{2}$ yields

$$
a_{1}\left\{\left[1+\phi \alpha-\left(\phi \alpha+\lambda \rho_{n}\right) a_{1}-\lambda \rho_{n} b_{1}\right]^{2} \sigma_{\nu}^{2} \sigma_{z}^{2}+\left(\sigma_{z^{\prime}}^{2}+\sigma_{z}^{2}\right)\left(\phi^{2} \sigma_{z}^{2}+\sigma_{x}^{2}\right)\right\}=\sigma_{n}^{2}\left(\phi^{2} \sigma_{z}^{2}+\sigma_{x}^{2}\right)
$$


Now, using the expressions for $a_{1}$ and $b_{1}$ given by $\langle 20\rangle$ it can be seen that

$$
b_{1} / a_{1}=-H_{v} H_{n} \sigma_{u}^{2} /\left(H_{u t}^{2} \sigma_{u}^{2}+H_{x}^{2} \sigma_{x}^{2}\right)
$$

Using the definitions of the $H^{\prime}$ 's given by $\langle 17\rangle-\langle 19\rangle$ in this expression, a bit of manipulation yields

$$
b_{1}=\frac{-\phi(1+\phi \alpha) \sigma_{u}^{2} a_{1}+\phi\left(\phi \alpha+\lambda \rho_{v}\right) \sigma_{u}^{2} a_{1}^{2}}{\left(\phi^{2}+\lambda \rho_{u} a_{1}\right) \sigma_{z}^{2}+\sigma_{x}^{2}}
$$

Substituting this for $b_{1}$ in $\langle 30\rangle$, and multiplying through by $\left[\left(\phi^{2}+\lambda \rho_{u} a_{1}\right) \sigma_{u}^{2}+\sigma_{x}^{2}\right]^{2}$, it can be shown that

$$
\begin{aligned}
& a_{1}\left\{\left[1+\phi \alpha-\left(\phi \alpha+\lambda \rho_{v}\right) a_{1}\right] \cdot\left[\left(\phi^{2}+\lambda \rho_{u} a_{1}\right) \sigma_{u}^{2}+\sigma_{x}^{2}\right]+\lambda \rho_{u} \phi \dot{\sigma}_{u}^{2}\left[(1+\phi \alpha) a_{1}\right.\right. \\
& \left.\left.-\left(\phi \alpha+\lambda \rho_{v}\right) a_{1}^{2}\right]\right\}^{2} \sigma_{v}^{2} \sigma_{z}^{2}+\left(\phi^{2} \sigma_{u}^{2}+\sigma_{x}^{2}\right)\left[\left(a_{1}-1\right) \sigma_{u}^{2}+a_{1} \sigma_{z}^{2}\right] \cdot\left[\left(\phi^{2}+\lambda \rho_{u} a_{1}\right) \sigma_{u}^{2}+\sigma_{x}^{2}\right]^{2}=0
\end{aligned}
$$

Inspection reveals that this is a fifth-order polynomial in $a_{1}$. The solution(s) for $a_{1}$ can then be used in $\langle 31\rangle$ to find the solution(s) for $b_{1}$. Then, with these solutions in hand, the above procedure can be repeated to find solutions for $a_{2}$ and $b_{2}$.

\section{Notes}

1. This is the reason that has been given for recent devaluations by countries as diverse as Botswana, Chile, and France. It is also the reason cited for the wave of competitive devaluations that swept the United States and Western Europe during the Great Depression.

2. Boyer's paper actually suggests that foregn exchange market intervention, and by implication exchange-rate policy, can be used to stabilize real output. Krugman and Taylor (1978) have recently argued that by redistributing income from labor to capital (which has a lower marginal propensity to spend) a devaluation is likely to be contractionary. They argue that policymakers should be awate of this possibility, and should stand ready to accompany devaluation with expenditure increasing rather than expenditure reducing policles. However, their message is in truth the same as in the works cited in the text-devaluations have real effects.

3. This assumption is not, of course, intended to describe teality but to explicitly introduce a rationale for the existence of imperfect information that is at the heart of much of the literature on the new classical macroeconomics (sce Barro, 1981 for a survey of this literature). This framework has recently been used by Harris and Purvis (1981) to examine the efficiency of the foreign exchange market, and by Kimbrough (1983) to study the role of monetary policy in an open economy and the stability of real output under alternative exchange rate regimes.

4. Kimbrough (1983) has extended this result to the open economy. He shows that when the exchange rate is flexible and agents possess incomplete and differential information, monetary policy can influence the distribution of real output by altering the information content of the exchange rate.

5. The nominal interest rate on foreign bonds is taken to be constant for simplicity. This assumption does, however, imply that unperceived changes in $v_{i}$ are associated with real interest rate changes abroad.

6. At a minimum this information consists of their local commodity price, the exchange rate, the foreign nominal interest rate, and a knowledge of the structure of the economy and its past history. Note that agents can calculate the current local foreign price, $P_{t}^{*}(q)$, from their knowledge of $P_{t}(z)$ and $S_{t}$.

7. This type of output supply function has its roots in Lucas and Rapping (1969).

8. This provides an alternative way of writing the relative price term. Letting $i_{t}(z)=i^{*}+\left(E_{q} S_{t+1}-S_{t}\right)$ be the opportunity cost of holding money as perceived by agents in market $z$, it can be shown using $\langle 1\rangle$ and $\langle 2\rangle$ that $r_{t}(z)=P_{f}(z)-E_{q} P_{t+1}+i_{f}(z)$.

9. No random term is included in $\langle 6\rangle$ because agents would know it through their observation of the exchange rate.

10. The main substantive features of the exchange-rate rule $\langle\sigma\rangle$ is that it implicitly assumes that policymakers do not have superior information (relative to private agents). If they did then the conclusions of Section III would be modified along well known lines. See Sargent and Wallace (1975) and Barro (1981) for discussions of this point. 
11. As noted earlier, this knowledge allows agents to deduce their local foreign price, $P_{t}^{*}(q)$. Therefore, explicitly including this price in agents' information sets would be redundant.

12. This point has been stressed by Kimbrough $(1982,1983)$ where it is shown that the difference in the information content of the exchange rate is one of the key distinctions between fixed and flexible exchange-rate regimes.

13. If this assumption were relaxed this would no longer be the case. In general, the foreign nominal interest rate and economy-wide shocks to foreign prices will be correlated so that knowledge of the former will be useful in forming expectations about the latter. Modifying the model in this way would alter the details but not the substance of the analysis that follows.

14. An interesting feature of $\langle 14\rangle$ and $\langle 15\rangle$ is that one of the regressors, $H_{n} v_{t}+H_{k} u_{t}+H_{x} x_{i}$, depends on the regression coefficients (the $a^{\prime}$ 's and the $b$ 's) as can be seen from $\langle 17\rangle-\langle 19\rangle$, and it would seem to be necessary to take this endogeneity into account in solving the information extraction problem confronting agents. The reason for the endogeneity of the regressor $H_{v} v_{t}+H_{x} u_{t}+H_{x} x_{t}$ is that it reflects the information content of the observed monetary aggregate which, as shown by $\langle 13\rangle$ and noted earlier, depends on market expectations. Since market expectations are simply an average of individual expectations, the information content of the observed monetary aggregate is determined along with the solution to the information extraction problem confronting agents. (This problem, the endogeneity of one of the pieces of information used by agents to make forecasts, is implicit in the models of Barro (1980), Weiss (1980, 1982), King (1982), and Kimbrough (1983), and appears to be a characteristic of rational expectations models with differential information.) However, in competitive equilibrium with many agents making forecasts, the endogeneity of the regressor $H_{t} v_{t}+H_{u} u_{t}+H_{x} x_{t}$ will not be taken into account. Any one agent in choosing his $a$ 's and $b$ 's (i.e., in forming his expectations) will treat market expectations as if they were given. That is, each agent acts like a price taker, an 'expectations taker' if you will, since changes in his own $a$ 's and $b$ 's given everyone elses will exert no influence on market expectations (which are simply an average of individual expectations). Therefore, each agent will treat the information content of the observed monetary aggregate as being given to him by the market, and hence will ignore the endogeneity of the regressor $H_{v} v_{t}+H_{t} u_{t}+H_{x} x_{t}$ in $\langle 14\rangle$ and $\langle 15\rangle$.

15. Note that these forecasts are not the best possible forecasts of $\nu_{t}$ and $u_{t}$ in the econometric sense because there is a sort of externality present since the orthogonality conditions do not take account of the endogeneity of the regressor $H_{k} v_{t}+H_{t} u_{t}+H_{x} x_{t}$. However, given the competitive structure of the market in wbich agents are operating these solutions yield the best possible forecasts an individual agent can make and are fully consistent with rational expectations. The equilibrium of this, and many other rational expectations models, is thus a Nash equilibrium.

16. This follows from the fact that $P_{t}(z)-S_{i}-P_{i-1}^{*}=v_{t}+z_{i}$ so that when one of the two shocks is absent local commodity price movements reveal with certainty the magnitude of the other shock.

17. It can be seen from $\langle 32\rangle$ that $\rho_{v}$ and $\rho_{u}$ will affect $a_{1}$. Similar results hold for $a_{2}, b_{1}$, and $b_{2}$.

18. When $\sigma_{x}^{2}=0$ there are still three shocks present $\left(u_{t}, v_{t}\right.$, and $\left.x_{t}\right)$ and they cannot all be inferred accurately from the two pieces of information agents possess, $P_{t}(z)-S_{t}-P_{t-1}^{*}=v_{t}$ and $\hat{M}_{t}-M_{t}^{0}$.

19. Because exchange-rate policy works by in essence altering the information at agents' disposal, it follows that to be effective it must be able to influence the information content of some variable that agents observe at the time they make their supply and demand decisions. In the present setup that variable is the observed monetary aggregate, but in other models other variables could conceivably play the same role. For example, if a nontraded good were introduced into the model and if its demand were made to depend on real cash balances, then exchange-rate policy could possibly influence the distribution of real output by altering the information content of the market price of nontraded goods.

20. As can be seen from $\langle 13\rangle$ these choices for the policy parameters also imply that the observed monetary aggregate contains information only on the aggregate shocks component, $(1+\phi \alpha) v_{t}+\phi u_{t}+x_{t}$. Whether or not these values of the policy parameters will be optimal from the standpoint of stabilizing real output is another question.

21. This point has recently been argued by Havrilesky (1982).

22. This can be seen from a straightforward application of the recursive projection formula with agents first viewed as using the information conveyed by market prices and then updating using the additional information conveyed by the observed monetary aggregate. When a reliable monetary aggregate is in fact observed, agents' forecasts of $v_{t}$ will be more accurate and, as can be seen from $\langle 22\rangle$, this will reduce the variance of real output about its full curtent information value. See Sargent (1979) for a discussion of the recursive projection formula. 
23. It should be noted that the small country assumption may be crucial for this result because it guarantees that the information content of prices is not altered by the release of monetary information. It would be interesting to see whether or not this result extends to cases where the information content of prices is affected by the release of monetary information.

\section{References}

Barro, R.J., 'A Capital Market in an Equllibrium Business Cycle Model', Econometrica, September 1980, 48: 1393-1417.

Barro, R.J., 'The Equilibruum Approach to Business Cycles', in his Money, Expectations, and Business Cycles, New York: Academic Press, 1981.

Boyer, R.S., 'Optimal Foreign Exchange Market Intervention', J. Pol. Econ., December 1978, 86: $1045-1055$.

Chan, K.S., 'Rational Expectations and Optimal Foreign Exchange Regimes', Can. J. Econ., February 1982, 15: 164-174.

Dornbusch, R. AND S. Fischer, Macroeconomics, New York: McGraw-Hill, 1981.

Harris, R.G. AND D.D. Purvis, 'Diverse Information and Market Efficiency in a Monetary Model of the Exchange Rate', Econ. J., December 1981, 91: 829-847.

Havrilesky, 'T., 'Optimal Information Policy'. Working Papers in Economics No. 82-02, Duke University, 1982.

Kimbrough, K.P. 'Aggregate Information and the Role of Monetary Policy in an Open Economy'. Unpublished manuscript, Duke University, 1982.

Kimbrough, K.P., 'The Information Content of the Exchange Rate and the Stability of Real Output under Alternative Exchange-Rate Regimes', J. Int. Money and Finance, April 1983, 2: 27-38.

KInG, R.G., 'Monetary Information and Monetary Neutrality', J. Monet. Econ., March 1981, 7: 195-206.

King, R.G., 'Monetary Policy and the Information Content of Prices', J. Pol. Econ., April 1982, 90: 247-279.

Krugman, P. and L. Taylor, 'Contractionary Effects of Devaluation', J. Int. Econ., August 1978, 8: 445-456.

Leiderman, L., 'Expectations and Output-Inflation Tradeoffs in a Fixed-Exchange Rate Economy', J. Pol. Econ., December 1979, 87: 1285-1306.

Lucas, R.E., Jr. and L.A. Rapping, 'Real Wages, Employment, and Inflation', J. Pol. Econ., September/October 1969, 77: 721-754.

Meade, J.E., The Balance of Payments, London: Oxford University Press, 1951.

Mundell, R.A., 'Capıtal Mobility and Stabilization Policy under Fixed and Flexible Exchange Rates', Can. J. Econ. and Pol. Sa., November 1963, 19: 475-485.

Sargent, T.J., Macroeconomic Theory, New York: Academic Press, 1979.

Sargent, T.J. And N. Wallace, 'Rational Expectations, the Optimal Monetary Instrument and the Optimal Money Supply Rule', J. Pol. Econ., April 1975, 83: 241-254.

Turnovsky, S.J., 'The Effects of Devaluation and Foreign Price Disturbances under Rational Expectations', J. Int. Econ., February 1981, 11: 33-60.

Weber, W.E., 'Output Variability under Monetary Policy and Exchange Rate Rules', J. Pol. Econ., August 1981, 89: 733-751.

Werss, L., 'The Role for Active Monetary Policy in a Rational Expectations Model', J. Pol. Econ., April 1980, 88: 221-233.

Werss, L., 'Information Aggregation and Policy', Rer'. Econ. Stud., January 1982, 49: 31-42. 